•研究报告・

\title{
海南岛淡水蟹类分布格局与多样性保护
}

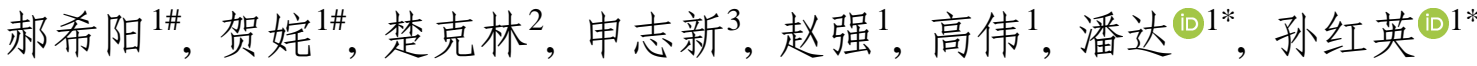

1. 南京师范大学生命科学学院江苏省生物多样性与生物技术重点实验室, 南京 210023; 2. 生态环境部南京环境科学研究所自然保护地研 究中心，南京 210042; 3. 海南省海洋与渔业科学院淡水渔业研究所, 海口 571126

摘要: 热带岛屿生物多样性是全球生物多样性保护研究的热点之一。海南岛是中国面积最大的热带岛屿, 丰富独特的淡水蟹 类是维持岛内淡水生态系统功能完整性的关键类群。本文通过多年野外调查，综合历史及最新文献资料，对海南岛淡水蟹类 物种多样性及其现状进行调查和评估, 并对淡水蟹类物种多样性保护现状进行了分析讨论。研究发现, 海南岛淡水蟹类物种 多样性分布中心位于中南部山地, 主要集中于中部的霸王岭、鹦哥岭和狝猴岭, 南部的五指山和吊罗山, 以及西南部的尖峰 岭一带。其物种多样性整体上呈现中南部山地高、平原台地低的特点。根据《IUCN物种红色名录濒危等级和标准》对海南 岛淡水蟹类物种现状的评估结果显示，全岛受威胁淡水蟹类物种的占比为 $16.7 \%$ 。基于分布区预测，以海南热带雨林国家公 园为主体的保护地对淡水蟹类潜在适宜分布区的覆盖度明显优于此前碎片化的各级保护区。本文研究结果显示, 海南岛淡水 蟹类的总体生存状况良好，但一部分山地或平原种类处于受胁状态。国家公园体制的建立有望为岛内淡水蟹类物种多样性保 护提供前所未有的机遇。基于物种多样性分布格局开展淡水蟹类等淡水生物多样性监测, 有助于促进海南岛淡水生态系统完 整性的长效保护与可持续发展。

关键词: 海南岛; 淡水蟹类; 空间分布格局; IUCN红色名录; 物种分布区预测; 海南热带雨林国家公园

郝希阳, 贺姹, 楚克林, 申志新, 赵强, 高伟, 潘达, 孙红英 (2021) 海南岛淡水蟹类分布格局与多样性保护. 生物多样性, 29, 605-616. doi: 10.17520/ biods.2020326.

Hao XY, He C, Chu KL, Shen ZX, Zhao Q, Gao W, Pan D, Sun HY (2021) The distribution pattern and biodiversity conservation of freshwater crabs in Hainan Island. Biodiversity Science, 29, 605-616. doi: 10.17520/biods.2020326.

\section{The distribution pattern and biodiversity conservation of freshwater crabs in Hainan Island}

Xiyang Hao ${ }^{1 \#}$, Cha $\mathrm{He}^{1 \#}$, Kelin $\mathrm{Chu}^{2}$, Zhixin Shen ${ }^{3}$, Qiang Zhao ${ }^{1}$, Wei Gao ${ }^{1}$, Da Pan ${ }^{(1)}{ }^{*}$, Hongying Sun ${ }^{(11 *}$

1 Jiangsu Key Laboratory for Biodiversity and Biotechnology, College of Life Sciences, Nanjing Normal University, Nanjing 210023

2 Protected Areas Research Center, Nanjing Institute of Environmental Sciences, Ministry of Ecology and Environment, Nanjing 210042

3 Freshwater Fisheries Research Institute, Hainan Academy of Ocean and Fisheries Sciences, Haikou 571126

\section{ABSTRACT}

Aims: The biodiversity of tropical islands is a popular topic in global biodiversity conservation research. Hainan Island is the largest tropical island in China. Freshwater crabs are a keystone species for freshwater ecosystems in Hainan Island. The aims of this study were thus to identify the distribution pattern and assess the threat status of freshwater crabs in Hainan Island.

Methods: In this study, we used field surveys and conducted a literature review to investigate the species diversity and conservation status for freshwater crabs in Hainan.

Results: Our results indicate that the diversity hotspots for freshwater crab species on Hainan Island are located in the south-central mountainous area (especially Bawangling, Yinggeling, Mihouling, Wuzhi Mountain, Diaoluo Mountain and Jianfengling). Freshwater crab diversity is higher in the central and southern mountains and lower in the plains. According to the IUCN Red List Categories and Criteria, 16.7\% of freshwater crab species on Hainan Island are

收稿日期: 2020-08-12; 接受日期: 2020-10-16

基金项目: 国家自然科学基金(31772427)

\# 共同第一作者 Co-first authors

* 共同通讯作者 Co-authors for correspondence. E-mail: sunhongying@njnu.edu.cn; dapan@njnu.edu.cn 
threatened. Diversity conservation effectiveness analyses demonstrate that the Hainan Tropical Rainforest National Park system as leading part of Hainan's protected area system is better than the previous system (which was several fragmented nature reserves) for covering the potential distribution areas of freshwater crabs. Overall, conservation status for freshwater crabs in Hainan Island is favorable, but some species are threatened.

Conclusion: The establishment of the national park system is expected to provide unprecedented opportunities for the conservation of freshwater crab species diversity in Hainan Island. Monitoring freshwater biological diversity based on the distribution pattern of species diversity will promote the long-term protection and sustainable development for freshwater ecosystems on Hainan Island.

Key words: Hainan Island; freshwater crabs; spatial distribution pattern; IUCN Red List; species distribution prediction; Hainan Tropical Rainforest National Park

海南岛是中国面积最大的热带岛屿, 发育和保 存了中国生物量最大的岛屿热带雨林和季雨林, 并 借以支撑和维持了丰富独特的生物区系, 是中国最 具有保护价值与可持续发展潜力的生物多样性热 点地区之一。岛内优异的热带湿润气候和复杂的地 理环境孕育了大量的岛屿特有动物。其中受到广泛 关注和保护的动物类群大多为脊椎动物 (郑作新和 谭耀匡, 1973; 中国水产科学研究院, 1986; 黄勇和 王跃招, 2011; Bryant et al, 2016), 淡水无脊椎动物 多样性的保护研究一直未受到足够重视。

淡水蟹类是一类营淡水底栖生活的大型无脊 椎动物, 它们大多生活于热带、亚热带至暖温带的 内陆和岛屿的淡水环境中, 喜活动于清洁的流动水 体如溪流、河流、湖泊, 也在水田、池塘、沟渠以 及热带雨林和季雨林低洼的积水林地中活动, 对水 质条件极其敏感。中国淡水蟹类的物种多样性居全 球第一(Cumberlidge et al, 2009; 楚克林等, 2018), 分布于台湾岛和海南岛的岛屿物种是其中重要的 组成部分。

海南岛独特的地理位置和热带海岛生物区系, 为淡水蟹类的繁衍生息提供了适宜的环境条件。然 而, 近年来随着岛内人口增长和经济活动加剧, 城 镇化建设和耕地面积增加使土地利用形式发生巨 大改变, 加之过度使用杀虫剂等农药造成的水质污 染, 导致海南岛淡水栖息地衰退、热带雨林和季雨 林生境破碎化, 岛内独特的淡水生物如淡水蟹类等 类群的生存状况受到威胁。其中, 海南岛特有的一 种淡水蟹类东方海南溪蟹(Hainanpotamon orientale) 已被列入IUCN濒危物种红色名录(Cumberlidge et $\mathrm{al}, 2009$ )。此外, 因缺乏相关的数据资料, 岛内其他 淡水蟹类的生存状况尚未得到有效评估, 在《中国 物种红色名录(第三卷): 无脊椎动物》(汪松和解炎,
2005)中, 并没有评估包括海南岛淡水蟹类在内的 中国任何一种淡水蟹。

2020年4月, 国家林业和草原局(国家公园管理 局)与海南省人民政府联合颁布了《海南热带雨林国 家公园规划 (2019-2025年)》 (http://www.forestry. gov.cn) (以下简称《规划》)。《规划》整合了海南中 部山区各类自然保护地, 拟建立统一规范的热带雨 林国家公园管理保护体系。本文以2008-2019年期 间在海南岛进行淡水蟹类多样性调查获得的标本 数据为基础, 汇总相关文献记载, 综合分析海南岛 淡水蟹类物种多样性及其空间分布格局; 依据 《IUCN物种红色名录濒危等级和标准(3.1版)》, 全 面评估海南岛淡水蟹类物种濒危等级; 针对当前 《规划》制定的国家公园空间布局，评估该热带雨 林国家公园在海南岛淡水蟹类物种多样性保护中 的潜在作用。

本文系统调查和分析了海南岛淡水蟹类的地 理分布与物种多样性现状, 期望推进海南岛淡水蟹 类等淡水生物的多样性监测和生物多样性保护, 并 为海南岛热带雨林国家公园等保护区的生物多样 性保护管理与决策提供科学依据和可靠建议。

\section{材料和方法}

\section{1 调查区域、标本采集与分类鉴定}

本文于2008年、2012年及2019年调查了海南岛 淡水蟹类生物多样性。依据相关文献记录(戴爱云和 邢定介，1993，1994; 戴爱云和拍文·乃亚内，1994; Dai, 1995; 戴爱云, 1999; Yeo \& Naruse, 2007), 在 全岛范围内布设调查样线与样点, 以全面覆盖已有 海南岛淡水蟹类历史记录的市县和地点。同时, 在 前人调查未曾涉足的偏远地区和高海拔山地、台地 和山间盆地等地区着重展开调查。实际的野外调查 
样点数是文献记录样点数的 3 倍以上。

使用GPS记录采样点的经纬度等数据, 使用数 码相机记录采样点生境, 使用地笼、D型抄网或者 徒手法进行样品采集。采集获得的淡水蟹类标本浸 置于含95\%乙醇溶液的样品瓶中, 室温保存。标本 保存时, 按照采样点编号分别保存在样品瓶中, 在 硫酸纸标签上填写各样点编号、采样地点、采集日 期和采集人等信息, 置于瓶中, 在样品瓶外贴上同 样信息的标签。

使用实体显微镜 Nikon SMZ1500、Nikon SMZ645对标本及其附肢构造进行观察。参照《中 国动物志》(戴爱云, 1999) 以及相关文献(Yeo \& Naruse, 2007; Huang et al, 2020)对采集获得的标本 进行分类鉴定。通过与中国科学院国家动物标本馆 馆藏的模式标本进行比对, 对溪蟹科物种进行鉴 定。除2019年采集的部分标本外, 其余标本均保存 于南京师范大学生命科学学院生物多样性与生物 技术重点实验室。

\section{2 数据分析}

\subsection{1 物种多样性空间分布格局分析}

整理野外调查采样记录点和文献历史记录点 的经纬度数据, 编制海南岛淡水蟹类物种分布数据 集，根据各属内物种的分布点位，绘制各属淡水蟹 类在海南岛的地理分布区; 采用 $0.2^{\circ} \times 0.2^{\circ}$ 的网格 划分, 利用地理信息系统(Geographical Information Systems, GIS)的渔网功能和空间关联分析功能, 衡 量每个网格区域的物种丰富度(species richness, SR), 分析海南岛淡水蟹类的物种丰富度格局。

采用最大熵分布模型MaxEnt (v3.4.1) (Phillips et al, 2006)对海南岛淡水蟹类的潜在适生区进行生 态位建模(ecological niche modeling, ENM)。考虑到 MaxEnt模型得出较为准确的结果需要每个物种至 少 5 个不同的坐标值, 本文将 6 个点作为计算物种分 布时的最低标准。对分布点数超过 6 个(含 6 个)的 11 种淡水蟹类的潜在适生区进行生态位建模模拟分 析, 获得海南岛淡水蟹类潜在物种丰富度(potential species richness, PSR)。选择22个能够反映地形与气 候特征的环境变量(附录1)。其中 19 个反映当今气候 的变量(Bio1-Bio19)来自于Worldclim 2.0 数据库 (www.worldclim.org) (Stephen \& Hijmans, 2017); 海 拔(altitude)、坡度(slope)、坡向 (aspect) 3 个地形变量 来源于SRTM (Shuttle Radar Topography Mission) (https://eospso.gsfc.nasa.gov)。海南岛边界数据来源 于中国科学院资源环境科学数据中心 (http:// www.resdc.cn)。海南热带雨林国家公园图层来源于

《规划》(审图号: 琼S(2019)129号), 该图层通过 ArcGIS数字化后导入地图。将所有环境变量的栅格 像元精度重采样至30弧秒, 进行模型构建。

对于可建模物种, 首先使用MaxEnt进行初步 建模以篮选对模型贡献率大于零的变量。然后, 使 用 R 4.0.0 (http://www.r-project.org)中的ENMTools 软件包(Warren et al, 2019)对环境变量的共线性进 行检测, 对于两两Pearson相关系数大于 0.9 的变量, 仅选择对模型贡献度较大者以降低模型的复杂度。 最终, 每个物种保留3-8个环境变量进行最终建模。 设置随机测试数据的百分比为 $25 \%$, 使用MaxEnt模 型的自举重复(bootstrap)功能产生10个子模型, 计 算 10 个子模型在每个像元上输出的平均值作为该 物种的最终预测结果。为了识别潜在分布区, 使用 最大测试灵敏度和特异性(maximum test sensitivity plus specificity)作为区分适宜分布区与非适宜分布 区的阈值, 将物种分布概率图转化为 $0 / 1$ 二值分布 图。最大测试灵敏度和特异性被广泛应用于物种分 布模型的阈值选择, 可以最大化减少选择不适宜地 区的概率(Pearce \& Ferrier, 2000; Manel et al, 2001; Liu et al, 2011)。建模完成后使用受试者工作特征曲 线(receiver operating characteristic curve, ROC曲线) 下的面积值—AUC值 (area under curve, AUC)作 为模型模拟结果优良度的评判(Fielding \& Bell, 1997)。本研究中, 使用MaxEnt建模的结果检验其 AUC 值, 所预测的 11 个物种的 AUC 值均大于 0.75 (附录2), 说明其模型的预测能力良好。

对于物种分布记录点个数小于 6 的 4 个物种, 使 用HydroSHEDS 全球水文数据集(Lehner \& Grill, 2013)中的子流域(sub-basin)作为这4个物种的适宜 栖息地的 “替代模型”。该数据集是一系列多边形图 层, 它在全球范围内以分层嵌套的方式描绘了不同 级别(1-12级)子流域的边界, 目前已广泛应用于流 域分析、水文建模与淡水水生生物的保护研究 (Heiner et al, 2011; Tognelli et al, 2019)。本文使用第 12 级子流域图层, 以满足海南岛较小的土地面积及 一部分狭域分布物种的特点。将该物种的所有分布 点构成的最小外部包络多边形(minimum convex polygon, MCP)映射入 HydroSHEDS 的第 12 级子流 
域, 以由此构成的子流域集合作为该物种的适宜分 布区。对于只有 1 个记录点的物种, 以其分布点所在 的HydroSHEDS数据集的第12级子流域作为其适宜 分布区。将该适宜分布区图层转化为 $0 / 1$ 二值分布 图。最终, 将15种海南岛淡水蟹类物种的二值分布 图在ArcGIS中使用栅格叠加功能进行分布区的叠 加计算, 得到潜在物种丰富度图层。所有分布区的 制图均在ArcGIS 10.2中完成。

根据二值分布图中值为 1 的适宜分布区域像元 数量的大小, 按照所有物种分布区大小的中位数 $(6,585)$ 将海南岛淡水蟹类分为狭域分布种和广域分 布种(Chen et al, 2019)。

\subsection{2 物种受胁状况分析}

依据《IUCN物种红色名录濒危等级和标准(3.1 版)》(IUCN, 2001, 2012a, b) 对海南岛淡水蟹类的受 胁等级进行评估。IUCN将物种濒危等级列为: 绝灭 (Extinct, EX)、野外绝灭(Extinct in the Wild, EW)、 极危(Critically Endangered, CR)、濒危(Endangered, EN)、易危(Vulnerable, VU)、近危(Near Threatened, NT)、无危(Least Concern, LC)、数据缺乏(Data Deficient, DD)和未予评估(Not Evaluated, NE)等9个 等级。其中, CR、EN和VU三个等级被列为受威胁 (Threatened)等级。采用标准B, 应用各物种的分布 区 (extend of occurance, EOO)和占有面积 (area of occupancy, AOO), 综合野外调查所获得的种群分布 现状和生境变化情况, 对各物种的受胁等级进行评 估。对部分分布区狭窄的小种群物种, 若使用标准B 进行评估则会不可避免地提高其受胁等级。为了避 免这种情况, 按照Guidelines for Using the IUCN Red List Categories and Criteria (IUCN Standards and Petitions Committee, 2019), 对这类物种使用标准D2 进行评估。标准D2是通过占有面积(AOO)或分布点 数量, 同时结合目标物种是否有可能在外界条件干 扰下处于极危(CR)、甚至绝灭(EX)的风险进行评估。

Guidelines for Using the IUCN Red List Categories and Criteria明确规定(IUCN Standards and Petitions Committee, 2019), 对低于物种水平的 分类单元(如亚种、种群)进行评估之前, 需要对整个 物种进行详尽的评估。鉴于此前IUCN对海南非仿 溪蟹(Apotamonautes hainanensis)的评估结果为数据 缺乏, 故本文单独将海南非仿溪蟹作为一种进行评 估, 而不以各亚种分别评估。因此, 本文评估的海
南岛淡水蟹类物种共计12种。

\section{结果}

2.1 海南岛淡水蟹类的物种多样性与生态分布

共采集淡水蟹类标本 700 余号, 经鉴定，隶属 于2科5属15种(及亚种) (表1), 覆盖全部文献记述的 种类。海南岛淡水蟹类以溪蟹科为主, 包括非仿溪蟹 属(Apotamonautes)、海南溪蟹属(Hainanpotamon)、 新内溪蟹属 (Neotiwaripotamon) 和岩溪蟹属 (Calcipotamon)共4属11种 (及亚种), 占全部物种数 的73\%; 拟地蟹科仅有束腰蟹属(Somanniathelphusa) 1属4种, 占 $27 \%$ 。除海南溪蟹属和束腰蟹属之外, 其 余3个属均为海南岛特有属。已记述的全部15种(及 亚种)淡水蟹类均为海南岛特有(表1)。

统计本文野外调查记录的标本采集样点(合计 124个), 合并文献记载的历史样点, 总计获得海南 岛淡水蟹类分布样点164个, 调查样点遍及全省 19 个市县中的 16 个, 覆盖了海南岛已知有淡水蟹类分 布的区域, 以及此前未曾涉足调查淡水蟹类的区域 (图1A)。比较各属淡水蟹类在海南岛的地理分布区 (图1B-E), 可见分布最广的是束腰蟹属, 其地理分 布遍及中南部山地、西南滨海平原和丘陵、台地，向 北直抵南渡江下游冲积平原，在海南岛15个市县均 有分布(图1E), 该属物种主要分布于农田田埂、沟 渠，池塘、溪流、河流或湖泊岸边的泥洞中。分布 较广的是非仿溪蟹属(图1B)和海南溪蟹属(图1D), 两者的分布区主要集中于中南部山地，并向北延伸 至南渡江下游冲积平原。非仿溪蟹属物种是典型的 河流生态型淡水蟹类，多在山间溪流以及河流、湖 泊等水域栖息。该属的分布区向东可延伸至万泉河 下游的丘陵、台地和冲积平原，遍及 11 个市县; 该 属的物种其成体常栖息于山溪、河流与湖泊的石块 下，也会藏匿于河岸边石块下的缝隙中，幼体也见 于雨林地表积水的浅洞中, 洞深不足 $5 \mathrm{~cm}$ 。海南溪 蟹属的分布区遍及13个市县，常在山区丘陵、台地 的山坡上或河流冲积平原的田埂、地头掘穴而居， 在山地生境中其洞穴可深达 $1 \mathrm{~m}$ 余, 且蟹洞密集, 常成群穴居, 为典型的山地生态型淡水蟹。新内溪 蟹属与岩溪蟹属分布区狭窄，前者集中分布于中南 部山地(图1C), 后者仅见于霸王岭南部山间盆地。 新内溪蟹属与岩溪蟹属物种都属于典型的山地热 带雨林和季雨林生态型, 善于爬树, 常藏匿于雨林 
表1 海南岛淡水蟹类物种名录

Table 1 A checklist of the freshwater crabs in Hainan Island, China

\begin{tabular}{ll}
\hline 分类地位 Classification & 物种名 Species name \\
\hline 溪蟹科 Potamidae & \\
非仿溪蟹属 Apotamonautes* & 海南非仿溪蟹泮水亚种 Apotamonautes hainanensis banshuiensis* \\
& 海南非仿溪蟹霸王岭亚种 Apotamonautes hainanensis bawanglingensis* \\
& 海南非仿溪蟹指名亚种 Apotamonautes hainanensis hainanensis* \\
& 海南非仿溪蟹南林亚种 Apotamonautes hainanensis nanlinensis* \\
& 戴氏海南溪蟹 Hainanpotamon daia** \\
海南溪蟹属 Hainanpotamon & 府城海南溪蟹 Hainanpotamon fuchengense* \\
& 和乐海南溪蟹 Hainanpotamon helense* \\
& 东方海南溪蟹 Hainanpotamon orientale* \\
新内溪蟹属 Neotiwaripotamon* & 白新内溪蟹 Neotiwaripotamon whiteheadi* \\
& 尖峰新内溪蟹 Neotiwaripotamon jianfengense* \\
岩溪蟹属 Calcipotamon* & 紫光岩溪蟹 Calcipotamon puglabrum* \\
拟地蟹科 Gecarcinucidae & \\
束腰蟹属 Somanniathelphusa & \\
& 坝王束腰蟹 Somanniathelphusa bawangensis* \\
& 海南束腰蟹 Somanniathelphusa hainanensis* \\
& 琼山束腰蟹 Somanniathelphusa qiongshanensis* \\
& 通什束腰蟹 Somanniathelphusa tongzhaensis* \\
\hline
\end{tabular}

*海南岛特有属种 Endemic to Hainan Island, China
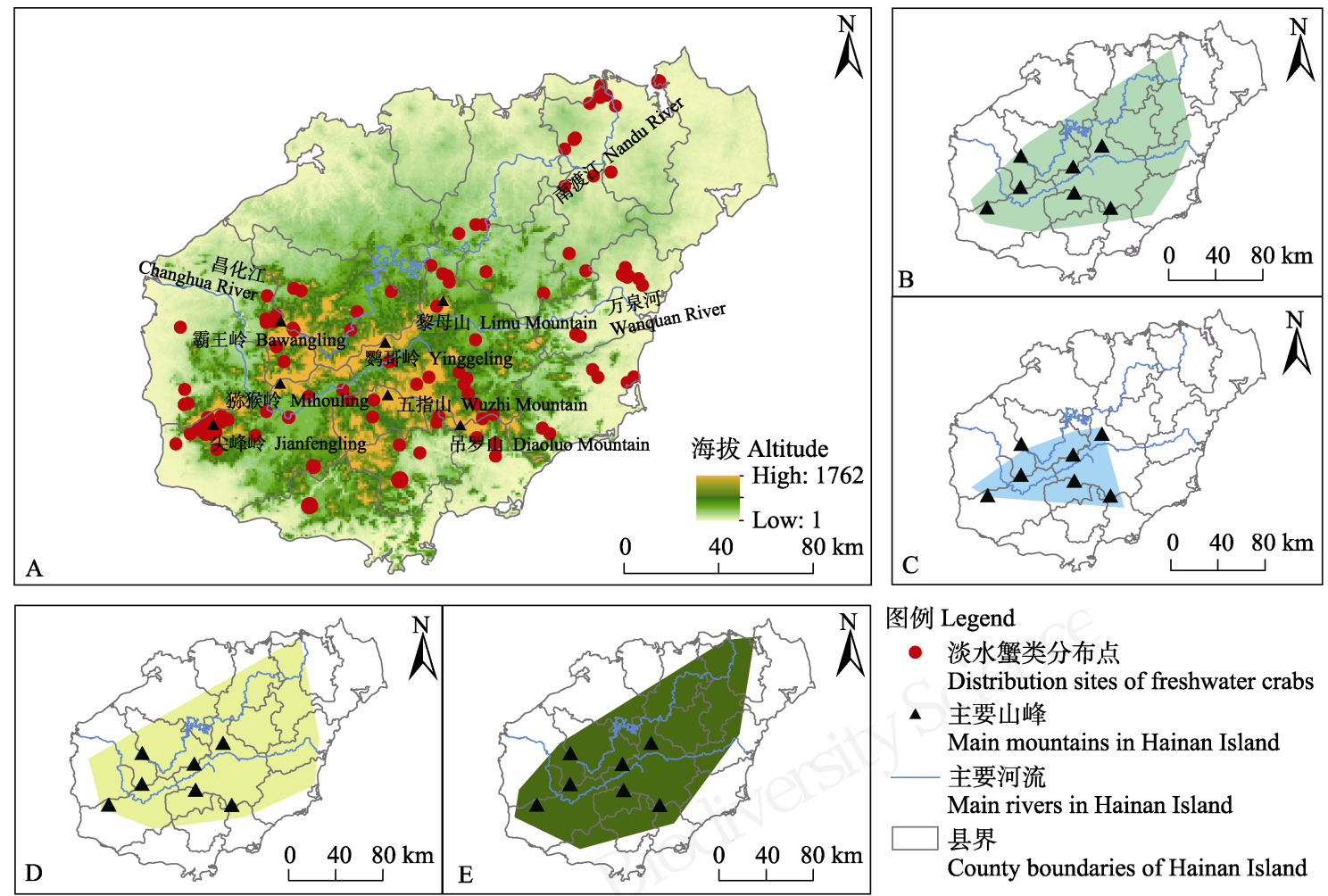

图1 海南岛淡水蟹类各属物种地理分布区域。A: 淡水蟹类分布点; B: 非仿溪蟹属物种分布区; C: 新内溪蟹属与岩溪蟹属 物种分布区; D: 海南溪蟹属物种分布区; E: 束腰蟹属物种分布区。

Fig. 1 Distribution area of different genera of freshwater crabs in Hainan Island. A, Distribution sites of freshwater crabs; B, Apotamonautes species distribution area; C, Newtiwaripotamon and Calcipotamon species distribution area; D, Hainanpotamon species distribution area; E, Somanniathephusa species distribution area. 
和季雨林中含水的树洞或岩石露头的缝隙中。

\section{2 淡水蟹类物种丰富度分布格局}

\subsection{1 基于 $0.2^{\circ} \times 0.2^{\circ}$ 网格的物种丰富度格局}

基于 $0.2^{\circ} \times 0.2^{\circ}$ 网格对物种丰富度格局的分析 显示, 海南岛淡水蟹类在空间分布上有 5 个物种多 样性分布中心(图2: a-e), 物种丰富度中南部地区较 高。这 5 个分布中心是: (1)霸王岭_鸭哥岭-猕猴岭多 样性中心(图2: a), 包括霸王岭、鸭哥岭和猕猴岭及 其间的山间丘陵和盆地, 在东北方沿南渡江延伸至 黎母山附近的山地、丘陵和台地。该中心淡水蟹类 物种共计8种(隶属2科5属)。(2)五指山-吊罗山多样 性中心(图2: b), 包括五指山、吊罗山以及山间和周 围的丘陵、台地。该中心物种丰富度达到7种(隶属2 科4属)。(3)尖峰岭多样性中心(图2: c), 包括尖峰岭 山地及其周围的丘陵、台地。该中心物种丰富度达 到5种(隶属2科4属)。另外两个物种多样性中心分别 位于万泉河和南渡江下游的丘陵、台地和河流冲积 平原(图2: d, e)。两者物种丰富度均达到了5 种, 均隶 属2科3属。

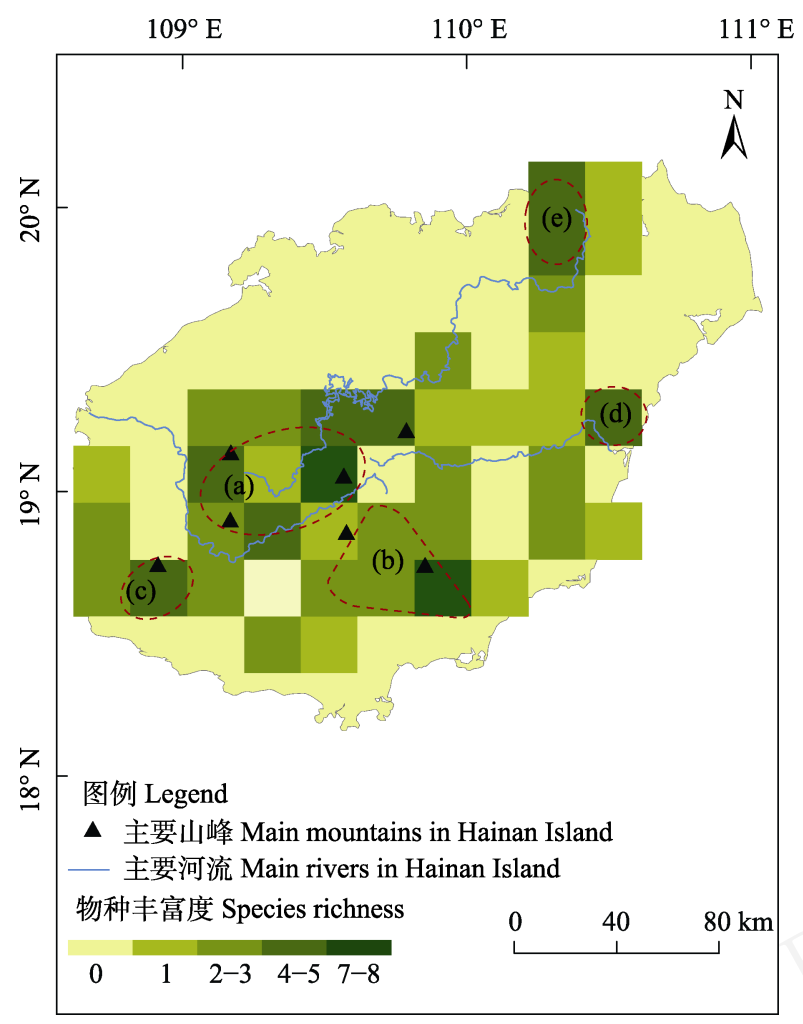

图2 以 $0.2^{\circ}$ 网格为操作单元的海南岛淡水蟹类物种丰富度 格局。a-e: 物种多样性分布中心。

Fig. 2 The species richness pattern of freshwater crabs of Hainan Island based on $0.2^{\circ}$ grids. a-e, Diversity hotspots.

\subsection{2 潜在物种丰富度及其分布格局}

基于MaxEnt预测的海南岛淡水蟹类潜在物种 丰富度显示, 潜在物种丰富度热点地区集中在中南 部山地，可划分为 3 个物种多样性中心(图3: $\mathrm{a}-\mathrm{c}$ )。其 一为霸王岭-财可哥岭_猕猴岭中心(图3: a), 该中心平 均海拔 $672 \mathrm{~m}$, 年均降雨量 $1,528 \mathrm{~mm}$, 最冷月最低 温为 $12.0^{\circ} \mathrm{C}$, 区域内淡水蟹类物种多样性最高, 共 计2科5属7种; 其二为五指山-阿陀岭吊罗山(图3: b), 该中心平均海拔 $579 \mathrm{~m}$, 年均降雨量 $1,544 \mathrm{~mm}$, 最冷月最低温为 $12.8^{\circ} \mathrm{C}$, 区域内淡水蟹类共计 2 科 4 属7种; 第三为尖峰岭及其周边的山间丘陵和台地 (图 3: c), 该中心平均海拔 $685 \mathrm{~m}$, 年均降雨量 $1,436 \mathrm{~mm}$, 最冷月最低温为 $12.9^{\circ} \mathrm{C}$, 区域内淡水蟹 类共计2科4属6种。此外, 与吊罗山毗邻的东南部丘 陵、台地，以及南渡江下游冲积平原地区的淡水蟹 类物种多样性也较高, 分别达到了 2 科 3 属 4 种和 2 科 3属5种。总体来看, 海南岛淡水蟹类物种多样性的 空间分布呈现南高北低，物种丰富度从集中分布的 中南部山地向外围丘陵、台地和滨海平原辐射并逐 级降低的格局。

对环境因子的评估分析进一步显示，影响海南

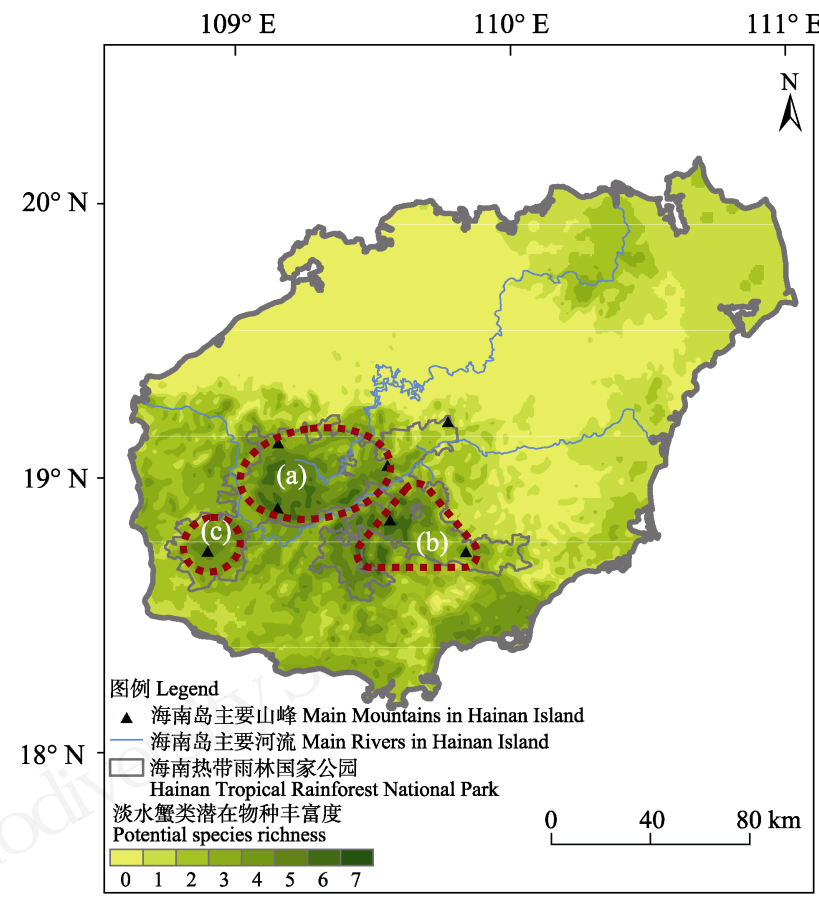

图3 海南岛淡水蟹类潜在物种丰富度。a-c: 潜在的物种多 样性分布中心。

Fig. 3 Potential species richness of freshwater crabs in Hainan Island. a-c, Potential diversity hotspots. 
表2 海南岛淡水蟹类物种受胁等级评估

Table 2 Threatened categories of freshwater crabs in Hainan Island

\begin{tabular}{lll}
\hline 种名 Species name & 受胁等级 Threatened categories & 所依据的标准 IUCN Redlist Criteria \\
\hline 海南非仿溪蟹 Apotamonautes hainanensis & LC & \\
戴氏海南溪蟹 Hainanpotamon daiae & LC & B1ab(i, ii, iii) + 2ab(i, ii, iii) \\
府城海南溪蟹 Hainanpotamon fuchengense & VU & LC \\
和乐海南溪蟹 Hainanpotamon helense & VU & B1ab(iii) + 2ab(iii) \\
东方海南溪蟹 Hainanpotamon orientale & NT & \\
白氏新内溪蟹 Neotiwaripotamon whiteheadi & LC & \\
尖峰新内溪蟹 Neotiwaripotamon jianfengense & NT \\
紫光岩溪蟹 Calcipotamon puglabrum & LC \\
坝王束腰蟹 Somanniathelphusa bawangensis & LC \\
海南束腰蟹 Somanniathelphusa hainanensis & LC \\
琼山束腰蟹 Somanniathelphusa qiongshanensis & LC \\
通什束腰蟹 Somanniathelphusa tongzhaensis &
\end{tabular}

岛淡水蟹类分布的主要环境因子包括最湿季度均 温(Bio8)、温度季节性变化(Bio4)、最暖季度降水量 (Bio18)与坡向(aspect) (附录3)。

\section{3 海南岛淡水蟹类物种濒危等级评估}

对海南岛 12 种淡水蟹类濒危等级的评估结果 显示 (表 2), 东方海南溪蟹和府城海南溪蟹 (Hainanpotamon fuchengense) 的等级为易危(VU), 其余 10 种均为近危(NT)或无危(LC)。受胁物种的占 比为 $16.7 \%$ 。

\section{3 讨论}

\section{1 海南岛淡水蟹类多样性分布格局}

本研究在2008-2019年期间, 共采集到15种(及 亚种)海南岛淡水蟹类, 占中国全部淡水蟹类物种 总数的 $4.5 \%$; 占中国岛屿淡水蟹类物种总数的 $26 \%$ 。在全 国25个有淡水蟹类分布的省份(包括直辖 市、自治区和特别行政区)中, 海南省淡水蟹类物种 多样性排名第11位。

本研究基于网格的物种丰富度空间分布格局 分析与基于生态位模型的适宜分布区预测分析显 示出基本一致的物种丰富度空间分布特点。中南部 山地的淡水蟹物种多样性最为丰富, 物种数共计 14 种(及亚种) (隶属2科5属), 占海南岛已记述物种(含 亚种)的 $93 \%$, 是岛内淡水蟹物种多样性分布的热点 区域。这些种类主要集中分布于以霸王岭、尖峰岭、 五指山等山地和山间丘陵、盆地组成的 3 个分布中 心, 包括霸王岭-鸭哥岭-猕猴岭, 五指山一吊罗山,
以及尖峰岭。从地质历史和古气候的变化上看, 更 新世冰期、间冰期交替旋回和与之相应的海平面高 度的变化致使周期性的海侵与海退事件发生(张兰 生, 2012)。推测在间冰期的大海侵期间, 海拔较高 的海南岛中南部山地为淡水蟹类等依赖岛屿淡水 生境的生物提供了避难所。冰期海退后, 一部分淡 水蟹类由高海拔山区向低海拔的山间丘陵、盆地扩 散, 并拓展至海水退却后露出的广大河流冲积平原 或滨海平原。因而, 海南岛海拔较高的山地区域成 为淡水蟹类物种多样性分布的中心。另一方面, 海 南岛中南部山地的植被主要为热带雨林性常绿润 叶林、热带常绿阔叶雨林和热带半常绿阔叶季雨林 (刘明光, 2010), 这为喜湿暖的淡水蟹类提供了优越 的栖息地条件。从环境质量来看, 海南岛中南部山 地热带雨林与季雨林生态系统的人类扰动指数明 显低于其外围农田和建设用地密布的丘陵、台地与 河流冲积平原、滨海平原等地区(侯鹏等, 2018), 适 宜的环境条件为该地区淡水蟹类的种群繁衍和多 样性可持续发展提供了重要保障。

本文使用MaxEnt对分布样点信息丰足的11种 (及亚种)海南岛淡水蟹类的潜在适生区进行了成功 模拟。另外 4 种(及亚种)因掌握的分布样点较少, 仅 采用水文生态学中的“子流域” 作为此类物种潜在适 生区的替代模型。虽然使用子流域模拟淡水生物分 布区的做法在国际上已被广泛接受, 但相较于统计 学模型对物种分布区的模拟, 其结果仍然存在一定 程度的不确定性。因此, 有必要通过后续的定期野 
外调查获得更多一手的物种分布数据, 从而丰富和 完善海南岛淡水蟹类物种分布的本底资料。

\section{2 海南岛淡水蟹多样性保护现状}

本研究对早期文献记载的淡水蟹类分布样点 进行了实地调查, 以确认各物种的种群现状。调查 结果发现, 文献记载的14种淡水蟹类在野外实地调 查中均被再次采获并记录, 这提示海南岛绝大多数 淡水蟹类物种的生存状况良好。值得注意的是, 2008年, 基于当时文献资料的记载, 东方海南溪蟹 被 IUCN 物种红色名录评估为濒危 (EN) (Cumberlidge et al, 2009)。Esser和Cumberlidge (2008) 提出, 该种淡水蟹类自1979年后未再被发现, 认为 造成这种淡水蟹类濒危的主要因素是大规模砍伐 森林造成的栖息地破坏。本文调查期间, 对东方海 南溪蟹的种群现状进行了周密地野外调查。结果显 示, 该种淡水蟹类广泛见于白沙县、昌江县、琼中 县和屯昌县等地, 实际有收获的样点共计 6 个(见于 4 县 5 镇), 获得标本 (经形态分类鉴定确认) 共计 33 号。据此认为, 2008年IUCN对东方海南溪蟹评估得 出的濒危等级是在该物种文献数据相对不完善、缺 乏深入野外实地调查情况下得出的, 其结论存在一 定局限性。本次重新评估针对该种开展了大量野外 调查, 获得了基于凭证标本水平的详实分布数据。 调查还发现, 该物种的分布区主要集中于霸王岭周 边山地与山间盆地, 以及黎母山北部的山间丘陵与 台地, 其中, 霸王岭周边原生林地环境受到较好保 护, 植被覆盖程度明显优于黎母山。海南岛自1994 年全面禁伐天然林以来, 岛内森林覆盖率逐年上升, 2010年岛内森林生态系统占全省生态系统的面积 已达63.72\% (林媚珍和张镱锂, 2000; 徐海根等, 2013)。十余年来, 岛内山地森林植被覆盖率的大面 积回升, 为淡水蟹类的种群恢复提供了良好条件。 依据《IUCN物种红色名录濒危等级和标准》中对 于受胁等级调整的规则, 综合本文野外调查所得的 分布数据与栖息地环境质量等信息, 对该物种进行 重新评估, 结果将其等级由濒危调整至易危。该种 目前面临的主要威胁是人类活动所导致的栖息地 退化或丧失。比如在黎母山周边地区, 区内村镇密 布, 植被覆盖呈现小斑块状。对原生植被的过度开 垦、砍伐等活动导致直接的土地利用形式的改变与 间接的环境污染，对该物种的存续造成不利影响。

此外, 本文基于调查获得的标本数据, 对其余
海南岛淡水蟹类进行了物种红色名录重新评估。本 轮评估显示, 府城海南溪蟹由数据缺乏调整为易危; 白氏新内溪蟹(Neotiwaripotamon whiteheadi)由数据 缺乏调整为近危; 紫光岩溪蟹 (Calcipotamon puglabrum)评估为近危; 海南非仿溪蟹等 8 种由数 据缺乏调整为无危。海南岛淡水蟹类受胁物种共计 2 种, 占比为 $16.7 \%$ 。易危种府城海南溪蟹主要分布 于南渡江下游的冲积平原, 常栖息于河漫滩、农田、 池塘及水渠的岸梗边。根据本文实际野外调查, 该 物种的若干历史分布点位的生境条件已改变为城 镇建设用地，栖息地退化、丧失、片断化的情况严 重, 且该区域是海南岛人口密度最大的区域, 人类 活动对该种造成了极大影响。

需要注意的是, 白氏新内溪蟹与紫光岩溪蟹为 典型的山地生态型淡水蟹, 均分布于中南部山地与 山间盆地区域。虽然这两个物种分布点数均较少, 特别是紫光岩溪蟹分布范围极其狭窄, 但综合野外 实地采样情况, 该两种淡水蟹目前所处生境均为海 南岛南部较为原始的热带雨林区域, 处于霸王岭国 家级自然保护区与海南热带雨林国家公园的庇护 中, 极少受到人类活动干扰。该区域近年来受到干 旱影响。但综合分析海南岛以往数十年干旱历史, 发现干旱在海南岛并非罕见极端气候，1961-2004 年的四十余年间曾发生过4次较大规模的严重干旱 (俞胜宾等, 2006)。野外调查发现, 在干旱季节, 河 流、溪流水位大幅下降时, 淡水蟹类会迁往低洼阴 凉处或藏匿于岩石下以躲避干旱(戴爱云, 1999)。紫 光岩溪蟹栖息于由风化形成的充满水的石灰岩露 头的缝隙中或充满水的树洞中, 表明该种对栖息环 境的选择具有多样性, 并不仅限于单一的栖息环 境。由于该种于近期被发现, 对其生态和生物学研 究尚不透彻, 需要通过进一步野外实地调查加深对 该种的认知。

因此, 有必要对海南岛北部地区的淡水蟹类尤 其是南渡江中下游冲积平原的受胁淡水蟹类进行 持续的野外调查与监测, 及时掌握其多样性状况。

\section{3 海南岛淡水蟹类多样性保护成效的预测与 分析}

海南岛1960年建立第一个自然保护区一一尖 峰岭国家级自然保护区, 截至2015年底, 已建立49 个各级自然保护区以及数量众多的诸如森林公园 等的自然保护地, 共同构建了海南岛多样化的自然 
保护地体系。在海南热带雨林国家公园建立以前, 海南热带雨林国家公园范围内共有各级自然保护 区和森林公园19个, 其面积之和约占国家公园总面 积的 $55.51 \%$ 。但各个碎片化的保护地人为削弱了海 南岛热带雨林-季雨林的生态完整性, 在保护管理 上相互独立的保护地之间形成保护空缺地带, 这在 一定程度上加剧了生境破碎化对野生动物保护造 成的不利影响，阻碍了野生动物的种群扩散和基因 交流。海南热带雨林国家公园的建立，整合优化了 现有的其他类型保护地，构建了新的以国家公园为 主体的自然保护地体系, 使海南岛中南部保护地面 积显著扩展; 景观类型的多样性增加, 涵盖了山地 和山地间的丘陵、台地和山间盆地等, 将过去碎片 化的栖息地连接起来, 强化了热带雨林-季雨林的 生态完整性, 为野生动物的生存提供了足够空间, 为种群扩散和交流拓宽了生态廊道。本文应用GIS 的栅格叠加分析功能, 对比建立海南热带雨林国家 公园前后两种保护区布局对海南岛淡水蟹类适宜 分布区的覆盖程度，以此预测和评估以国家公园为 主体的保护地体系对淡水蟹类的保护成效(表3)。可 以发现, 在原有的保护地体系中, 已有的国家级与 地方各级保护区对区域内各种淡水蟹类适宜分布 区的覆盖度极其有限(均低于 $30 \%$ ), 平均覆盖度仅
10.83\%。而国家公园布局下，淡水蟹类适宜分布区 的受覆盖程度大幅提升，平均覆盖度达到 $30.39 \%$ 。 尤其是对分布区仅局限于海南岛中南部山地的部 分呈狭域分布的淡水蟹类, 如紫光岩溪蟹、白氏新 内溪蟹、尖峰新内溪蟹 (Neotiwaripotamon jianfengense) 和东方海南溪蟹, 其适宜分布区受保 护区覆盖的程度超过 $40 \%$ 。可以预见，海南热带雨 林国家公园的建立将有利于海南岛淡水蟹类物种 多样性的恢复, 有利于海南岛特有淡水蟹类多样性 的长效保护。

需要指出的是, 在海南岛仍有部分淡水蟹类的 适宜分布区未受到国家公园或保护区的良好庇护。 其中受胁物种——府城海南溪蟹仅分布于海南岛 北部南渡江河流冲积平原与熔岩台地的部分区域。 当前, 不论是各级保护区还是海南热带雨林国家公 园均未对其潜在分布区起到保护作用。和乐海南溪 蟹 (Hainanpotamon helense) 、琼山束 腰 蟹 (Somanniathelphusa qiongshanensis)及海南束腰蟹(S. hainanensis)经过评估虽未在红色名录受胁等级内, 但这些种的潜在分布区被各级保护区和海南热带 雨林国家公园覆盖的比例均未超过2\%。因此，南渡 江下游平原是海南岛淡水蟹类保护最为显著的空 缺地带。

表3 海南热带雨林国家公园内各级保护区与海南热带雨林国家公园对海南岛淡水蟹类潜在适宜分布区的覆盖程度

Table 3 The coverage of nature reserves and Hainan Tropical Rainforest National Park on the distribution of Hainan freshwater crab species

\begin{tabular}{llllll}
\hline 种名 Species name & $\begin{array}{l}\text { 分布区像元数 } \\
\text { Pixel of presence }\end{array}$ & $\begin{array}{l}\text { NRs覆盖像元数 } \\
\text { Pixel of presence } \\
\text { covered by NRs }\end{array}$ & $\begin{array}{l}\text { NRs覆盖比例 } \\
\text { Coverage of } \\
\text { NRs (\%) }\end{array}$ & $\begin{array}{l}\text { NP覆盖的像元数 } \\
\text { Pixel of presence } \\
\text { covered by NP }\end{array}$ & $\begin{array}{l}\text { NP覆盖比例 } \\
\text { Coverage of NP } \\
\text { (\%) }\end{array}$ \\
\hline 紫光岩溪蟹 Calcipotamon puglabrum* & 203 & 55 & 27.09 & 203 & 100.00 \\
府城海南溪蟹 Hainanpotamon fuchengense* & 1,125 & 0 & 0.00 & 0 & 0.00 \\
白氏新内溪蟹 Neotiwaripotamon whiteheadi* & 2,233 & 328 & 14.69 & 1,312 & 58.76 \\
和乐海南溪蟹 Hainanpotamon helense* & 3,752 & 0 & 0.00 & 0 & 0.00 \\
尖峰新内溪蟹 Neotiwaripotamon jianfengense* & 5,729 & 1,534 & 26.78 & 3,354 & 58.54 \\
东方海南溪蟹 Hainanpotamon orientale* & 6,317 & 1,338 & 21.18 & 2,694 & 42.65 \\
琼山束腰蟹 Somanniathelphusa qiongshanensis & 6,853 & 0 & 0.00 & 0 & 0.00 \\
海南束腰蟹 Somanniathelphusa hainanensis & 7,023 & 0 & 0.00 & 0 & 0.00 \\
坝王束腰蟹 Somanniathelphusa bawangensis & 7,872 & 65 & 0.83 & 441 & 5.60 \\
通什束腰蟹 Somanniathelphusa tongzhaensis & 12,175 & 1,254 & 10.30 & 3,190 & 26.20 \\
海南非仿溪蟹 Apotamonautes hainanensis & 12,323 & 1,835 & 14.89 & 4,621 & 37.50 \\
戴氏海南溪蟹 Hainanpotamon daiae & 14,331 & 2,044 & 14.26 & 5,073 \\
均值 Average & $6,661.33$ & 704 & 10.83 & 1,741 & 35.40 \\
\hline
\end{tabular}

*狭域分布种: NP: 海南热带雨林国家公园; NRs: 海南热带雨林国家公园范围内的自然保护区.

* Narrowly distributed species; NP, Hainan Tropical Rainforest National Park; NRs, Nature reserves. 


\section{4 保护建议}

海南省北部南渡江下游平原与台地等地区保 护区数量极少, 因此, 对该地区淡水蟹类多样性及 其赖以为生的淡水水源地和淡水生态环境的保护 应予以关注, 从而有效弥补该地区淡水生态系统多 样性保护的空缺。

当前, 中国尚无一个自然保护区和国家公园将 淡水蟹类列入其保护对象。淡水蟹类作为淡水底栖 大型无脊椎动物群的关键功能物种, 在淡水生态系 统的能量流动、物质循环和生态服务中起到极为重 要的作用。Ng等(2015b)对新加坡特有的极危种淡水 蟹Johora singaporensis的野外调查发现, 土壤酸化、 其他动物类群的捕食和竞争很可能是导致该物种 在其原生栖息地消失的原因。在被评估为极危状态 后, 该物种成为新加坡重点保护物种, $\mathrm{Ng}$ 等随即为 其制定了一项包含物种野外种群监测、室内育种等 的多方面的保护策略。在保护行动实施后, 通过大 量针对该物种的野外调查与监测, 发现了该物种在 原先武吉知马保护区内一新的健康繁殖的种群 $(\mathrm{Li}$ et al, 2015; Ng et al, 2015a, b), 虽然目前该物种尚未 脱离极危级别, 但是对其采取的保护行动为该物种 的存续提供了新的保障。这是目前在保护区内针对 单个无脊椎动物开展保护行动的生动案例 (Kawai \& Cumberlidge, 2016)。国家公园建设需要关注包括 淡水生态系统在内的整个热带雨林生态系统的功 能完整性。针对淡水生态系统的保护是热带雨林生 态系统保护中的重要一环, 而针对淡水蟹类等淡水 底栖动物类群的保护是淡水生态系统保护的重要 组成部分。因而需要着重关注淡水蟹类等淡水底栖 动物类群的生存状况。如将国家公园范围内受胁与 近危物种(如东方海南溪蟹、紫光岩溪蟹)等典型山 地生态型淡水蟹类纳入国家公园重要保护物种名 录, 针对性开展相关物种监测与保护工作。目前国 内针对淡水蟹类的相关保护行动处于空白状态, 而 本次海南国家公园的建设有望为海南岛淡水蟹类 的保护提供新的机遇。

建立淡水水源地优先保护区或相关的淡水水 生动物保护地是开展淡水水生动物特别是淡水蟹 类保护的重要措施。由于海南岛北部平原与台地地 区人为干扰强度较大, 且该地区分布着诸如府城海 南溪蟹、东方海南溪蟹、海南非仿溪蟹、琼山束腰 蟹、海南束腰蟹、通什束腰蟹(Somanniathelphusa tongzhaensis)等多种淡水蟹类, 其中府城海南溪蟹 和东方海南溪蟹为受胁种, 因此该地区淡水蟹类及 其生境同样需要受到重视。自然保护区的建设应该 建立在与区域经济发展相协调的基础上(蒋志刚等, 1997), 考虑到海南岛北部地区环境与经济发展状 况, 在此地全面建立保护区的可行性较小。但是可 以通过建立淡水水源地优先保护区或相关的淡水 水生动物保护地以完善海南岛北部地区陆地保护 体系。如南渡江流域水库密布, 承担着流域内防洪、 蓄水灌溉、供水等重要功能。可依托这些相邻贯通 的水库、渠道等水源地保护区域, 建立完整相连通 的淡水水生动物保护地, 改善零散的森林或植被斑 块之间的连通性，以达到对淡水蟹类等淡水水生生 物的保护效果。淡水蟹类物种对环境变化敏感, 并 且依赖森林斑块所维持的良好水质(Cumberlidge et al, 2009), 因此保护淡水蟹类尤其要注重原生林地 的保护。同时, 还需要对处于受胁状态的淡水蟹类 进行长期监测, 以尽可能早地探查到物种在野外所 受到的威胁, 以便及时开展相应的物种保育行动。 如对于分布在中南部山地的部分近危物种, 需要定 期开展种群生存状况的调查与评估工作。

致谢: 海南省海口市林业局二级调研员郭建博士、 中国热带农业科学院热带作物品种资源研究所首 席专家王祝年研究员、海南师范大学王力军教授、 梁伟教授等在野外标本采集与调查工作中给予指 导和帮助, 黄超博士提供紫光岩溪蟹生态照片, 鲁士悦先生参与部分野外调查工作, 一并谨致谢 忱!

\section{ORCID}

潘达 (D) https://orcid.org/0000-0001-5445-6423

孙红英 (1) https://orcid.org/0000-0003-2311-1814

\section{参考文献}

Bryant JV, Gottelli D, Zeng X, Hong X, Chan BPL, Fellowes JR, Zhang Y, Luo J, Durrant C, Geissmann T, Chatterjee HJ, Turvey ST (2016) Assessing current genetic status of the Hainan gibbon using historical and demographic baselines: Implications for conservation management of species of extreme rarity. Molecular Ecology, 25, 3540-3556.

Chen CW, Chen CS, Wang YP (2019) Ecological correlates of extinction risk in Chinese amphibians. Diversity and Distributions, 25, 1586-1598. 
Cheng TH, Tan YK (1973) On the birds of Hainan. II. Acta Zoologica Sinica, 19, 405-416. (in Chinese with English abstract) [郑作新, 谭耀匡 (1973) 海南岛的鸟类. II. 动物 学报, 19, 405-416.]

Chinese Academy of Fishery Sciences (1986) The Freshwater and Estuary Fishes of Hainan Island. Guangdong Science and Technology Press, Guangzhou. (in Chinese) [中国水产 科学研究院 (1986) 海南岛淡水及河口鱼类志. 广东科 技出版社, 广州.]

Chu KL, Ma XP, Zhang ZW, Wang PF, Lü LN, Zhao Q, Sun HY (2018) A checklist for the classification and distribution of China's freshwater crabs. Biodiversity Science, 26, 274-282. (in Chinese with English abstract) [楚克林, 马晓 萍, 张泽伟, 王鹏飞, 吕琳娜, 赵强, 孙红英 (2018) 中 国淡水蟹分类与分布名录(十足目: 拟地蟹科, 溪蟹科). 生物多样性, 26, 274-282.]

Cumberlidge N, Ng PKL, Yeo DCJ, Magalhães C, Campos MR, Alvarez F, Naruse T, Daniels SR, Esser LJ, Attipoe FYK, Clotilde-Ba FL, Darwall W, McIvor A, Baillie JEM, Collen B, Ram M (2009) Freshwater crabs and the biodiversity crisis: Importance, threats, status, and conservation challenges. Biological Conservation, 142, 1665-1673.

Dai AY (1995) On a new genus and two new species of freshwater crabs from Hainan Island, China (Crustacea: Decapoda: Brachyura: Potamidae). Acta Zootaxonomica Sinica, 20, 391-397.

Dai AY (1999) Fauna Sinica • Arthropoda • Crustacea • Malacostraca • Decapoda • Parathelphusidae, Potamidae. Science Press, Beijing. (in Chinese with English abstract) [戴爱云 (1999) 中国动物志. 节肢动物门. 甲壳动物亚 门·软甲纲. 十足目・束腹蟹科, 溪蟹科. 科学出版社, 北 京.]

Dai AY, Naiyanetr P (1994) A revision of genus Tiwaripotamon Bott, 1970, the freshwater crabs from China (Decapoda: Brachyura: Potamidae). Sinozoologia, 11, 47-72. (in Chinese with English abstract) [戴爱云, 拍文·乃 亚内 (1994) 中国淡水蟹类内溪蟹属的修订 (十足目: 短 尾派: 溪蟹科). 动物学集刊, 11, 47-72.]

Dai AY, Xing DJ (1993) A study on Apotamonautes from Hainan Island, China (Decapods: Brachyura). Sinozoologia, 10, 63-72. (in Chinese with English abstract) [戴爱云, 邢 定介 (1993) 海南岛非仿溪蟹的研究(十足目, 短尾派). 动物学集刊, 10, 63-72.]

Dai AY, Xing DJ (1994) On Somanniathephusa from Hainan Island, China (Decapods: Parathelphusidae). In: Memorial Volume Dedicated to the Hundredth Anniversary of the Birthday of the Late Prof. Sisan CHEN (Z. CHEN) (ed. Chen YZ), pp. 97-108. China Science and Technology Press, Beijing. (in Chinese with English abstract) [戴爱云, 邢定介 (1994) 海南岛束腰蟹属的研究. 见: 纪念陈祯教 授诞辰一百周年论文集(陈阅增主编), 97-108页. 中国科 学技术出版社, 北京.]
Esser L, Cumberlidge N (2008) Hainanpotamon orientale. The IUCN Red List of Threatened Species 2008: e. T134773A4011437. https://www.iucnredlist.org/species/ 134773/4011437.html. (accessed on 2020-06-08)

Fielding AH, Bell JF (1997) A review of methods for the assessment of prediction errors in conservation presence/ absence models. Environmental Conservation, 24, 38-49.

Heiner M, Higgins J, Li XB (2011) Identifying freshwater conservation priorities in the Upper Yangtze River Basin. Freshwater Biology, 56, 89-105.

Hou P, Zhai J, Cao W, Yang M, Cai MY, Li J (2018) Evaluation on ecosystem changes and protection of the national key ecological function zones in mountainous areas of central Hainan Island. Acta Geographica Sinica, 73, 429-441. (in Chinese with English abstract) [侯鹏, 翟俊, 曹巍, 杨旻, 蔡明勇, 李静 (2018) 国家重点生态功能区 生态状况变化与保护成效评估一以海南岛中部山区国 家重点生态功能区为例. 地理学报, 73, 429-441.]

Huang C, Huang SZ, Shen ZX (2020) A new long-legged terrestrial freshwater crab, Calcipotamon puglabrum gen. nov. et sp. nov. (Crustacea: Decapoda: Potamidae), from Hainan Island, China. Zootaxa, 4766, 447-456.

Huang Y, Wang YZ (2011) Progress in the biogeography of amphibian and reptile in Hainan Island. Sichuan Journal of Zoology, 30, 304-309. (in Chinese with English abstract) [黄勇, 王跃招 (2011) 海南岛两栖爬行动物生物地理学 研究进展. 四川动物, 30, 304-309.]

IUCN (2001) IUCN Red List Categories and Criteria: Version 3.1. IUCN, Gland, Switzerland \& Cambridge, UK.

IUCN (2012a) IUCN Red List Categories and Criteria, Version 3.1, 2nd edn. IUCN, Gland, Switzerland \& Cambridge, UK.

IUCN (2012b) Guidelines for Application of IUCN Red List Criteria at Regional and National Levels, Version 4.0. IUCN, Gland, Switzerland \& Cambridge, UK.

IUCN Standards and Petitions Committee (2019) Guidelines for Using the IUCN Red List Categories and Criteria. Version 14. http://www.iucnredlist.org. (accessed on 2020-06-01)

Jiang ZG, Ma KP, Han XG (1997) Conservation Biology. Zhejiang Science and Technology Press, Hangzhou. (in Chinese with English summary) [蒋志刚, 马克平, 韩兴国 (1997) 保护生物学. 浙江科学技术出版社, 杭州.]

Kawai T, Cumberlidge N (2016) Conservation First: Strategic Planning to Save the Critically Endangered Singapore Freshwater Crab, Johora singaporensis. Springer International Publishing, Cham, Switzerland.

Lehner B, Grill G (2013) Global river hydrography and network routing: Baseline data and new approaches to study the world's large river systems. Hydrological Processes, 27, 2171-2186.

Li TJ, Lim WH, Cai YX (2015) A new locality of the Singapore freshwater crab Johora singaporensis (Crustacea: Brachyura: Potamidae) in the Bukit Timah Nature Reserve. 
Nature in Singapore, 8, 53-56.

Lin MZ, Zhang YL (2000) Dynamic changes of forest resources in Hainan and its sustainable development. Ecological Science, 19, 84-89. (in Chinese with English abstract) [林媚珍, 张镱锂 (2000) 海南岛森林资源的动 态变化及其可持续发展. 生态科学, 19, 84-89.]

Liu CR, White M, Newell G (2011) Measuring and comparing the accuracy of species distribution models with presenceabsence data. Ecography, 34, 232-243.

Liu MG (2010) Atlas of Physical Geography of China. SinoMaps Press, Beijing. (in Chinese) [刘明光 (2010) 中 国自然地理图集. 中国地图出版社, 北京.]

Manel S, Williams HC, Ormerod SJ (2001) Evaluating presence-absence models in ecology: The need to account for prevalence. Journal of Applied Ecology, 38, 921-931.

Ng DJJ, Sivasothi N, Cai YX, Davison GWH, Yeo DCJ (2015a) A new locality of the Singapore freshwater crab, Johora singaporensis (Crustacea: Brachyura: Potamidae). Nature in Singapore, 8, 31-35.

Ng DJJ, Yeo DCJ, Sivasothi N, Ng PKL (2015b) Conservation challenges and action for the Critically Endangered Singapore freshwater crab Johora singaporensis. Oryx, 49, 345-351.

Pearce J, Ferrier S (2000) Evaluating the predictive performance of habitat models developed using logistic regression. Ecological Modelling, 133, 225-245.

Phillips SJ, Anderson RP, Schapire RE (2006) Maximum entropy modeling of species geographic distributions. Ecological Modelling, 190, 231-259.

Stephen FE, Hijmans RJ (2017) WorldClim 2: New 1-km spatial resolution climate surfaces for global land areas. International Journal of Climatology, 37, 4302-4315.

Tognelli MF, Anderson EP, Jiménez SLF, Chuctaya J, Chocano L, Maldonado OJA, Mesa SL, Mojica JI, Carvajal VFM, Correa V, Ortega H, Rivadeneira RJF, Sánchez DP,
Cox NA, Hidalgo M, Jiménez PP, Lasso CA, Sarmiento J, Velásquez MA, Villa NFA (2019) Assessing conservation priorities of endemic freshwater fishes in the Tropical Andes region. Aquatic Conservation: Marine and Freshwater Ecosystems, 29, 1123-1132.

Wang S, Xie Y (2005) China Species Red List, Vol. III. Invertebrates. Higher Education Press, Beijing. (in Chinese) [汪松, 解炎 (2005) 中国物种红色名录(第三卷): 无脊椎 动物. 高等教育出版社, 北京.]

Warren DL, Matzke N, Cardillo M, Baumgartner J, Beaumont L, Huron N, Simões M, Iglesias TL, Dinnage R (2019) ENMTools. https://github.com/danlwarren/ENMTools. (accessed on 2020-05-01)

Xu HG, Cao MC, Wu J, Ding H (2013) An Inventory of Biodiversity of China. Science Press, Beijing. (in Chinese) [徐海根, 曹铭昌, 吴军, 丁晖 (2013) 中国生物多样性本 底评估报告. 科学出版社, 北京.]

Yeo DCJ, Naruse T (2007) A revision of the freshwater crab genus Hainanpotamon Dai, 1995 (Crustacea: Decapoda: Brachyura: Potamidae: Potamiscinae), with a redescription of Potamon (Potamon) orientale (Parisi, 1916) and descriptions of three new species. Zoological Science, 24, 1143-1158.

Yu SB, Zhai PM, Zhang Q (2006) Variation of characteristics of drought in Hainan Island during 1961-2004. Chinese Journal of Tropical Crops, 27, 113-115. (in Chinese with English abstract) [ 俞胜宾, 翟盘茂, 张强 (2006) 1961-2004海南岛干早演变特征分析. 热带作物学报, 27, 113-115.]

Zhang LS (2012) Paleogeography of China: The Formation of China's Natural Environment. Science Press, Beijing. (in Chinese) [张兰生 (2012) 中国古地理: 中国自然环境的 形成. 科学出版社, 北京.]

(责任编委: 李新正 责任编辑: 间文杰)

\section{附录 Supplementary Material}

附录1 19个生物气候因子和3个地形因子的描述

Appendix 1 The description of 19 bioclimatic variables and 3 topographic factors

https://www.biodiversity-science.net/fileup/PDF/2020326-1.pdf

\section{附录2 基于MaxEnt模型模拟海南岛11种淡水蟹类预测分布结果的AUC值}

Appendix 2 The AUC value of predicted distribution of 11 freshwater crabs in Hainan Island based on MaxEnt model https://www.biodiversity-science.net/fileup/PDF/2020326-2.pdf

\section{附录3 海南岛11种基于MaxEnt建模的淡水蟹类物种主要环境因子贡献率}

Appendix 3 The contribution of the main environment variables of the 11 freshwater crab species based on MaxEnt in Hainan Island

https://www.biodiversity-science.net/fileup/PDF/2020326-3.pdf 
郝希阳, 贺姹, 楚克林, 申志新, 赵强, 高伟, 潘达, 孙红英 (2021) 海南岛淡水蟹类分布格局与多样性保护. 生物多样性, 29, 605616. http://www.biodiversity-science.net/CN/10.17520/biods.2020326

附录1 19 个生物气候因子和 3 个地形因子的描述

Appendix 1 The description of 19 bioclimatic variables and 3 topographic factors

\begin{tabular}{|c|c|}
\hline 变量 Variable & 描述 Description \\
\hline Bio1 & 年均温 Annual mean temperature \\
\hline Bio2 & 平均温度日较差 Mean diurnal temperature range \\
\hline Bio3 & 等温性 Isothermality \\
\hline Bio4 & 温度季节性变化 Temperature seasonality \\
\hline Bio5 & 最热月最高温 Maximum temperature of warmest month \\
\hline Bio6 & 最冷月最低温 Minimum temperature of coldest month \\
\hline Bio7 & 年温度变化范围 Temperature annual range \\
\hline $\operatorname{Bio8}$ & 最湿季度均温 Mean temperature of wettest quarter \\
\hline Bio9 & 最干季度均温. Mean temperature of driest quarter \\
\hline Bio10 & 最暖季度均温 Mean temperature of warmest quarter \\
\hline Bio11 & 最冷季度均温 Mean temperature of coldest quarter \\
\hline Bio12 & 年平均降水量 Annual precipitation \\
\hline Bio13 & 最湿月降水量 Precipitation of wettest month \\
\hline Bio14 & 最干月降水量 Precipitation of driest month \\
\hline Bio15 & 降水量变异系数 Precipitation seasonality \\
\hline Bio16 & 最湿季度降水量 Precipitation of wettest quarter \\
\hline Bio17 & 最干季度降水量 Precipitation of driest quarter \\
\hline Bio18 & 最暖季度降水量 Precipitation of warmest quarter \\
\hline Bio19 & 最冷季度降水量 Precipitation of coldest quarter \\
\hline Alt & 海拔 Altitude \\
\hline Slope & 坡度 Slope \\
\hline Aspect & 坡向 Aspect \\
\hline
\end{tabular}


郝希阳，贺姹，楚克林，申志新，赵强，高伟，潘达，孙红英 (2021) 海南岛淡水蟹类分布格局与多样性保护. 生物多样性, 29, 605616. http://www.biodiversity-science.net/CN/10.17520/biods.2020326

附录2 基于MaxEnt模型模拟海南岛11种淡水蟹类预测分布结果的AUC值

Appendix 2 The AUC value of predicted distribution of 11 freshwater crabs in Hainan Island based on MaxEnt model

\begin{tabular}{ll}
\hline 物种 Species & AUC值 AUC value \\
\hline 海南非仿溪蟹霸王岭亚种 Apotamonautes hainanensis bawanglingensis & 0.882 \\
海南非仿溪蟹指名亚种 Apotamonautes hainanensis hainanensis & 0.776 \\
海南非仿溪蟹南林亚种 Apotamonautes hainanensis nanlinensis & 0.940 \\
戴氏海南溪蟹 Hainanpotamon daiae & 0.811 \\
和乐海南溪蟹 Hainanpotamon helense & 0.943 \\
东方海南溪蟹 Hainanpotamon orientale & 0.847 \\
尖峰新内溪蟹 Neotiwaripotamon jianfengense & 0.899 \\
坝王束腰蟹 Somanniathelphusa bawangensis & 0.817 \\
海南束腰蟹 Somanniathelphusa hainanensis & 0.846 \\
琼山束腰蟹 Somanniathelphusa qiongshanensis & 0.822 \\
通什束腰蟹 Somanniathelphusa tongzhaensis & 0.795 \\
\hline
\end{tabular}


郝希阳，贺姹，楚克林，申志新，赵强，高伟，潘达，孙红英 (2021) 海南岛淡水蟹类分布格局与多样性保护. 生物多样性, 29, 605616. http://www.biodiversity-science.net/CN/10.17520/biods.2020326

附录3 海南岛11种基于MaxEnt建模的淡水蟹类物种主要环境因子贡献率

Appendix 3 The contribution of the main environment variables of the 11 freshwater crab species based on MaxEnt in Hainan Island

\begin{tabular}{|c|c|c|}
\hline $\begin{array}{l}\text { 物种 } \\
\text { Species }\end{array}$ & $\begin{array}{l}\text { 主要环境因子 } \\
\text { Main environment variables }\end{array}$ & $\begin{array}{l}\text { 贡献率 } \\
\text { Contribution percentage (\%) }\end{array}$ \\
\hline 海南非仿溪蟹霸王岭亚种 & 海拔(Alt) & 50.7 \\
\hline Apotamonautes hainanensis & 最暖季度降水量(Bio18) & 17.6 \\
\hline \multirow[t]{3}{*}{ bawanglingensis } & 坡向(Slope) & 15.4 \\
\hline & 温度季节性变化(Bio4) & 10.6 \\
\hline & 年平均降水量(Bio12) & 5.7 \\
\hline 海南非仿溪蟹指名亚种 Apotamonautes & 最湿季度均温(Bio8) & 61.9 \\
\hline hainanensis hainanensis & 温度季度性变化(Bio4) & 38.1 \\
\hline 海南非仿溪蟹南林亚种 Apotamonautes & 最干月降水量(Bio14) & 89.5 \\
\hline hainanensis nanlinensis & 温度季度性变化(Bio4) & 10.5 \\
\hline \multirow[t]{5}{*}{ 戴氏海南溪蟹 Hainanpotamon daiae } & 最湿季度均温(Bio8) & 54.9 \\
\hline & 最干月降水量(Bio14) & 17.1 \\
\hline & 最暖季度降水量(Bio18) & 13.8 \\
\hline & 坡向(Aspect) & 12.2 \\
\hline & 年温度变化范围(Bio7) & 2.0 \\
\hline \multirow[t]{5}{*}{ 和乐海南溪蟹 Hainanpotamon helense } & 最干季度均温(Bio9) & 64.7 \\
\hline & 降水量变异系数(Bio15) & 28.3 \\
\hline & 坡向(Aspect) & 5.6 \\
\hline & 最湿季度降水量(Bio16) & 1.0 \\
\hline & 最湿月降水量(Bio13) & 0.4 \\
\hline \multirow[t]{5}{*}{ 东方海南溪蟹 Hainanpotamon orientale } & 年温度变化范围(Bio7) & 34.7 \\
\hline & 最湿季度均温(Bio8) & 26.9 \\
\hline & 坡向(Aspect) & 24.7 \\
\hline & 最冷季度降水量(Bio19) & 8.5 \\
\hline & 最暖季度降水量(Bio18) & 5.2 \\
\hline 尖峰新内溪蟹 Neotiwaripotamon & 最湿季度均温(Bio8) & 43.2 \\
\hline \multirow[t]{3}{*}{ jianfengense } & 最冷季度降水量(Bio19) & 30.1 \\
\hline & 坡向(Aspect) & 13.9 \\
\hline & 最暖季度降水量(Bio18) & 12.8 \\
\hline 坝王束腰蟹 Somanniathelphusa & 等温性(Bio3) & 78.3 \\
\hline \multirow[t]{3}{*}{ bawangensis } & 最冷季度降水量(Bio19) & 10.8 \\
\hline & 坡度(Slope) & 8.2 \\
\hline & 最暖季度降水量(Bio18) & 1.7 \\
\hline
\end{tabular}


郝希阳，贺姹，楚克林，申志新，赵强，高伟，潘达，孙红英 (2021) 海南岛淡水蟹类分布格局与多样性保护. 生物多样性, 29, 605616. http://www.biodiversity-science.net/CN/10.17520/biods.2020326

\begin{tabular}{lll}
\hline 物种 & 主要环境因子 & 贡献率 \\
Species & Main environment variables & 1.0 \\
& 坡向(Aspect) & 61.2 \\
海南束腰蟹 Somanniathelphusa & 海拔(Altitude) & 27.8 \\
hainanensis & 降水量变异系数(Bio15) & 6.9 \\
& 最湿月降水量(Bio13) & 4.1 \\
& 坡向(Slope) & 46.2 \\
琼山束腰蟹 Somanniathelphusa & 最暖季度降水量(Bio18) & 34.0 \\
qiongshanensis & 降水量变异系数(Bio15) & 19.9 \\
& 坡度(Slope) & 43.8 \\
通什束腰蟹 Somanniathelphusa & 最暖季度降水量(Bio18) & 24.8 \\
tongzhaensis & 最湿季度均温(Bio8) & 16.9 \\
& 年平均降水量(Bio12) & 14.6 \\
\hline
\end{tabular}

